\title{
Case Report: A World Trade Center (WTC) responder presenting with moderate stage dementia by age 57 , suggesting an extended severity of WTC-associated illness'
}

Sam Gandy ( $\sim$ samuel.gandy@mssm.edu ) Icahn School of Medicine at Mount Sinai https://orcid.org/0000-0001-6455-4721

\section{$\mathrm{H}$ Allison Bender}

Weill Cornell Medical School

Roberto Luccini

Florida International University https://orcid.org/0000-0002-9723-0237

Theophania Ashleigh

Icahn School of Medicine at Mount Sinai

Julie Ciardullo

Icahn School of Medicine at Mount Sinai

Sean A. P. Clouston

Stony Brook University https://orcid.org/0000-0002-6124-0329

Evelyn J Bromet

Stony Brook University https://orcid.org/0000-0002-2648-5793

Benjamin Luft

Stony Brook University https://orcid.org/0000-0001-9008-7004

\section{Mary Sano}

Icahn School of Medicine at Mount Sinai https://orcid.org/0000-0001-8889-2944

\section{Case Report}

Keywords: Neurodegeneration, Proteinopathy, Neuroinflammation

Posted Date: August 31st, 2021

DOl: https://doi.org/10.21203/rs.3.rs-846359/v1

License: (c) (1) This work is licensed under a Creative Commons Attribution 4.0 International License. Read Full License 


\section{Abstract}

Recent evidence indicates that World Trade Center Responders (WTCRs) are apparently at increased risk for a clinical syndrome that includes PTSD (posttraumatic stress disorder) and $\mathrm{MCl}$ (mild cognitive impairment). The association of these behavioral and cognitive symptoms was first described by Bromet, Luft, Clouston, and colleagues. No autopsy characterization of the syndrome has yet emerged, though biofluid and neuroimaging biomarker data support features of (1) progressive behavioral and cognitive dysfunction, (2) proteinopathy involving the appearance of neurodegeneration-related molecules in the peripheral circulation, and (3) a substantial regional loss of brain volume. Inciting factors such as inhalation of neurotoxins and/or psychological stressors (or a combination of both) have been proposed as contributory to the pathogenesis, but no definitive etiologic agent has been identified. In general, the subpopulation of WTCRs who developed PTSD and MCI were those with documentable extended exposure to the central feature of "Ground Zero" known as "the pile", and those who developed $\mathrm{MCl}$ were primarily a subgroup of those who had developed PTSD. Multiomic studies are underway to determine whether this subgroup might be enriched for genetic, genomic, and/or proteomic features that might have predisposed them to pathological responses to stress, environmental toxins, or both. In 2017, we had occasion to evaluate "E.T."; at that time, a 57-year-old bilingual (English and Spanish speaking) righthanded WTCR was referred to an urban medical center dementia specialty clinic for assessment of his cognitive and behavioral functioning. While early-onset dementia can occur sporadically, the proximity of E.T. to "the pile" at "Ground Zero", and the course of E.T.'s illness raise the possibility that WTC-related cognitive-behavioral syndromes may progress well beyond the stage of $\mathrm{MCl}$ to that of moderate dementia (and beyond) and that this progression may occur in the absence of full-blown PTSD.

\section{Case Report}

Recent evidence indicates that World Trade Center Responders (WTCRs) are apparently at increased risk for a clinical syndrome that includes PTSD (post-traumatic stress disorder) and $\mathrm{MCl}$ (mild cognitive impairment) ${ }^{1-10}$. The association of these behavioral and cognitive symptoms was first described by Bromet, Luft, Clouston, and colleagues ${ }^{1-3}$. No autopsy characterization of the syndrome has yet emerged, though biofluid and neuroimaging biomarker data support features of: (1) progressive behavioral and cognitive dysfunction, (2) proteinopathy involving the appearance of neurodegeneration-related molecules in the peripheral circulation, and (3) a substantial region loss of brain volume ${ }^{4-8}$. Inciting factors such as inhalation of neurotoxins and/or psychological stressors (or a combination of both) have been proposed as contributory to the pathogenesis, but no definitive etiologic agent has been identified ${ }^{8,9}$. In general, the subpopulation of WTCRs who developed PTSD and $\mathrm{MCl}$ were those with documentable extended exposure to the central feature of "Ground Zero" known as "the pile"1-3, and those who developed $\mathrm{MCl}$ were primarily a subgroup of those who had developed PTSD. Multi-omic studies are underway to determine whether this subgroup might be enriched for genetic, genomic, and/or proteomic features that might have predisposed them to pathological responses to stress, environmental toxins, or both $^{8-10}$. 
In 2017, we had occasion to evaluate "E.T.", at that time, a 57-year-old bilingual (English and Spanish speaking), right-handed WTCR referred to an urban medical center dementia specialty clinic for assessment of his cognitive and behavioral functioning. History and background information were obtained through a Clinical Interview with the patient and his wife.

According to E.T.'s wife, E.T.'s neurobehavioral syndrome began with changes in memory in 2013, leading to the diagnosis of early onset dementia in 2014. E.T.'s wife described his frequent repetition of statements or questions within minutes apparently unaware that he had made the same comments or asked the same questions just minutes earlier. She also described progressive word-finding difficulty and spatial disorientation during navigation (e.g., difficulty finding his way home while driving). As a result, E.T. was not permitted to operate a motor vehicle.

E.T.'s wife reported that he had begun to suffer mild depression and anxiety in 2011 but that neither symptom had been serious enough to require psychotropic medication. There was no diagnosis of PTSD, and there were no episodes of flashback re-experiences. There was also no history of stroke, TBI, seizures, or CNS infection. Other medical history included chronic cough, gout, hypothyroidism, benign prostatic hyperplasia, and hypertension. His medications included memantine, aspirin, amlodipineolmesartan, levothyroxine, colchicine, fish oil, and multivitamins. He and his wife described E.T.'s alcohol intake as "rare" for his entire life, including at the time of the evaluation. There was no history of use or abuse of tobacco or illicit or prescription medications.

E.T.'s family history was significant for coronary disease in both father and mother, diabetes (mother), and hypertension (mother). Both mother (age $72 \mathrm{yrs}$ ) and father (age $82 \mathrm{yrs}$ ) were living when E. T. was assessed neurologically. There is no known history of dementia in any members of E.T.'s family.

E. T. was born in Ecuador, and Spanish was his first language. He moved to the United States when he was five years old and learned English in US schools. There was no history of learning disability in childhood. He graduated from High School and completed three years of college. He joined the United States Marine Corps and was stationed in Parris Island, South Carolina. No recognized militaryassociated toxin exposure or battlefield engagement was included in E.T.'s Marine Corps service. He subsequently worked as a correction officer for approximately ten years, and as a police officer at the New York Police Department (NYPD) for another ten years.

E.T. was among the first responders at the World Trade Center Attacks on 09/11/2001, and he subsequently spent about three months as a supervisor of the digging operations at "Ground Zero" as part of his duty at the NYPD. He was routinely present near "the pile" where the WTC fell and where he was potentially exposed to aerosolized silicates and organic compounds. He retired from the NYPD in 2005 and worked as a ticket enforcement officer for the New York Metro Transit Authority until 2013, when he retired due to his cognitive impairment. E.T. reported using both English and Spanish daily and preferred to be tested in English. He had three children and three grandchildren from his first marriage. Details of the first marriage were not recorded or available. E.T.'s second marriage took place in 2016, soon before he was seen in our clinic. E.T. and his wife and son were living on Staten Island. 
The following tests were used to assess areas of intellect, premorbid abilities, language, memory, learning, visuospatial abilities, executive functioning, motor ability and processing speed: Record Review; Clinical Interview; Beck Anxiety Inventory (BAI); Beck Depression Inventory (BDIJ; Dementia Rating Scales second edition (DRS-2); Texas Functional living Scale (TFLS); and Vineland Adaptive Behavior Scales.

E.T. arrived at the neuropsychological testing appointment well-groomed, appropriately dressed, and was oriented only to person. His attention span was normal. Stimulus bound behaviors and mild impulsivity were observed during testing. Language comprehension appeared to be within normal limits, though repetition of questions and test instructions was often required. Pitch, prosody, and volume of speech were normal. Rate of speech was slow due to hesitation and anomia. His affect was sad and anxious, and he required multiple encouragements to complete the testing session. Overall, E.T. apparently put forth full effort on all tests administered.

E.T.'s premorbid intellectual abilities were estimated to fall within normal limits. In contrast, his current performance fell well below the cut-point required to support for a diagnosis of dementia. His MMSE was $<20$. His Dementia Rating Scale-2 (DRS-2) Total was below the $1^{\text {st }}$ percentile.

In terms of emotional status, E.T.'s responses on self-report mood inventories were not indicative of clinical levels of depression $(\mathrm{BDI}=5)$ or anxiety $(\mathrm{BAl}=2)$. Therefore, neither by history from his wife nor from observation and examination, PTSD was not part of the clinical picture.

In terms of activities of daily living, E.T. was unable to demonstrate his understanding of concepts of time and money calculations on a test of functional living, and he could not follow-up on a simple task following a 5-minute delay. Consistent with these pervasive adaptive function deficits, as indicated by responses on a questionnaire completed by his wife, E.T. was incapable of self-care, including an inability to manage finances, navigation, and day/night orientation.

$\left[{ }^{18} \mathrm{~F}\right]$ fluorodeoxyglucose positron emission tomography (FDG-PET; Figure) revealed bilateral temporoparietal hypometabolism consistent with the metabolic signature of Alzheimer's disease. Progressive neurological and psychiatric decline continued until E.T. died at age $59 \mathrm{yrs}$ from symptoms that were attributed to acute pulmonary edema but occurred in May, 2020, in the context of the COVID-19 pandemic.

Taken together, E.T.'s performance on this evaluation was marked by widespread cognitive difficulties, especially in the domains of attention, memory, executive functioning, and tasks of functional living. The range and scope of E.T.'s cognitive and adaptive functioning changes were used to justify a DSM-5 diagnosis of "Major Neurocognitive Disorder, without Behavioral Disturbance".

Estimated scaling of E.T.'s cognitive impairment (MMSE $<20$ and DRS-2 below the $1^{\text {st }} \%$ ile) indicated that his level of impairment progressed in severity substantially beyond that encompassed by the diagnosis of $\mathrm{MCl}$ and was well within the range associated with moderate dementia. While early onset dementia can occur sporadically, the proximity of E.T. to "the pile" at "Ground Zero", and the course of E.T.'s illness raises the possibility that WTC-related cognitive-behavioral syndromes may progress well beyond the 
stage of $\mathrm{MCl}$ to that of moderate dementia (and beyond) and that this progression may occur in the absence of full-blown PTSD. Despite the absence of autopsy neuropathology from any WTC-related cognitive-behavioral syndrome patient, progress in our understanding of the biomarker and multi-omic characterization of neurodegenerative diseases in general and of WTC-related cognitive-behavioral syndromes in particular should inform the determination of which features of neurodegeneration, proteinopathy, and/or neuroinflammation contribute to WTC-related cognitive-behavioral syndromes. This knowledge, in turn, could facilitate the design of clinical trials aimed at preserving cognitive and behavioral function in WTC-related cognitive-behavioral syndromes.

\section{Abbreviations}

WTCR World Trade Center Responder

PTSD Post-traumatic stress disorder

$\mathrm{MCl} \quad$ Mild cognitive impairment

\section{Declarations}

\section{Acknowledgements}

S.G. and M.S. acknowledge USPHS P30 AG066314 to Mary Sano. R.L. acknowledges CDC/NIOSH grant U010H011314.

Ethics approval and consent to participate

N/A clinical case report, postmortem

Consent for publication

Consent to publish patient details has been provided by his next of kin

\section{Availability of data and material}

$\mathrm{N} / \mathrm{A}$

Competing interests

None

Funding

Described above 
S.G., T.A., and H.A.B. wrote the first draft of the manuscript. J.C., R.G.L., E.J.B., S.A.P.C., and M.S. edited the manuscript. B. J. L. directs the WTC Program at the Renaissance School of Medicine at Stony Brook University.

\section{References}

1. Bromet EJ, Hobbs MJ, Clouston SA, Gonzalez A, Kotov R, Luft BJ. DSM-IV post-traumatic stress disorder among World Trade Center responders 11-13 years after the disaster of 11 September 2001 (9/11). Psychol Med. 2016 Mar;46(4):771 - 83. doi: 10.1017/S0033291715002184. PMID: 26603700; PMCID: PMC4754831.

2. Clouston SA, Kotov R, Pietrzak RH, Luft BJ, Gonzalez A, Richards M, Ruggero CJ, Spiro A 3rd, Bromet EJ. Cognitive impairment among World Trade Center responders: Long-term implications of reexperiencing the 9/11 terrorist attacks. Alzheimers Dement (Amst). 2016 Aug 19;4:67-75. doi: 10.1016/j.dadm.2016.08.001. PMID: 27626057; PMCID: PMC5011166.

3. Clouston S, Pietrzak RH, Kotov R, Richards M, Spiro A 3rd, Scott S, Deari Y, Mukherjee S, Stewart C, Bromet E, Luft BJ. Traumatic exposures, posttraumatic stress disorder, and cognitive functioning in World Trade Center responders. Alzheimers Dement (N Y). 2017 Oct 19;3(4):593-602. doi:

10.1016/j.trci.2017.09.001. PMID: 29201993; PMCID: PMC5700827.

4. Clouston SAP, Deri Y, Diminich E, Kew R, Kotov R, Stewart C, Yang X, Gandy S, Sano M, Bromet EJ, Luft BJ. Posttraumatic stress disorder and total amyloid burden and amyloid- $\beta$ 42/40 ratios in plasma: Results from a pilot study of World Trade Center responders. Alzheimers Dement (Amst). 2019 Feb 28;11:216-220. doi: 10.1016/j.dadm.2019.01.003. PMID: 30859121; PMCID: PMC6396325.

5. Clouston SAP, Deri Y, Horton M, Tang C, Diminich E, DeLorenzo C, Kritikos M, Pellecchia AC, SantiagoMichels S, Carr MA, Gandy S, Sano M, Bromet EJ, Lucchini RG, Luft BJ. Reduced cortical thickness in World Trade Center responders with cognitive impairment. Alzheimers Dement (Amst). $2020 \mathrm{Jul}$ 13;12(1):e12059. doi: 10.1002/dad2.12059. PMID: 32695871; PMCID: PMC7364857.

6. Kritikos M, Clouston SAP, Diminich ED, Deri Y, Yang X, Carr M, Gandy S, Sano M, Bromet EJ, Luft BJ. Pathway Analysis for Plasma $\beta$-Amyloid, Tau and Neurofilament Light (ATN) in World Trade Center Responders at Midlife. Neurol Ther. 2020 Jun;9(1):159-171. doi: 10.1007/s40120-020-00189-1. Epub 2020 Apr 30. PMID: 32350803; PMCID: PMC7229074.

7. Deri Y, Clouston SAP, DeLorenzo C, Gardus JD 3rd, Horton M, Tang C, Pellecchia AC, Santiago-Michels S, Carr MA, Gandy S, Sano M, Bromet EJ, Lucchini RG, Luft BJ. Selective hippocampal subfield volume reductions in World Trade Center responders with cognitive impairment. Alzheimers Dement (Amst). 2021 Mar 31;13(1):e12165. doi: 10.1002/dad2.12165. PMID: 33816755; PMCID: PMC8011041.

8. Daniels RD, Clouston SAP, Hall CB, Anderson KR, Bennett DA, Bromet EJ, Calvert GM, Carreón T, DeKosky ST, Diminich ED, Finch CE, Gandy S, Kreisl WC, Kritikos M, Kubale TL, Mielke MM, Peskind ER, 
Raskind MA, Richards M, Sano M, Santiago-Colón A, Sloan RP, Spiro A 3rd, Vasdev N, Luft BJ, Reissman DB. A Workshop on Cognitive Aging and Impairment in the 9/11-Exposed Population. Int J Environ Res Public Health. 2021 Jan 14;18(2):681. doi: 10.3390/ijerph18020681. PMID: 33466931; PMCID:

PMC7830144.

9. Stein CR, Cooney ML, Frank B, Bender HA, Winkel G, Lucchini RG. Mental health mediators of subjective cognitive concerns among World Trade Center responders. J Psychiatr Res. 2021 Aug;140:187-196. doi: 10.1016/j.jpsychires.2021.05.081. Epub 2021 Jun 2. PMID: 34118636.

10. Kuan PF, Clouston S, Yang X, Che C, Gandy S, Kotov R, Bromet E, Luft BJ. Single-cell transcriptomics analysis of mild cognitive impairment in World Trade Center disaster responders. Alzheimers Dement (Amst). 2021 Feb 20;13(1):e12154. doi: 10.1002/dad2.12154. PMID: 33665344; PMCID: PMC7896635.

\section{Figures}



\section{Figure 1}

Selected brain metabolic [18F]fluorodeoxyglucose positron emission tomography (PET) i mages from patient E.T., a WTC responder who developed moderate stage dementia by age 57 in the absence of a diagnosis of PTSD. Both images show the metabolic signature of asymmetrical bilateral parietal hypometabolism (arrows) interpreted as consistent with a diagnosis of early onset Alzheimer's disease (AD). 